\title{
The Effective Oncotic Pressure of Dextran ${ }^{1}$
}

\author{
John J. Mulcahy and Richard L. Malvin \\ Division of Urology, Department of Surgery, University of Kentucky, Lexington, Ky., \\ and Department of Physiology, University of Michigan, Ann Arbor, Mich.
}

Abstract. Measurement of plasma volume before and after the acute infusion of commercial dextran revealed that all brands tested were hyperoncotic by a factor of approximately 2 . By mixing $6 \%$ dextran with $0.9 \%$ saline in $1: 1$ proportion a $3 \%$ dextran solution was obtained which was nearly isoncotic in our dogs. The most likely explanation for the discrepancy is that the $6 \%$ solution contains a high proportion of molecules of lower molecular weight resulting in a greater oncotic pressure than predicted on the basis of the average molecular weight. In addition, this leads to a rapid loss of this solute from the blood. Clinicians and researchers should be aware of the possibility that the dextran preparation they are using is not truly isoncotic.

The use of dextran as a plasma expander is widespread in both clinical and laboratory areas. This solute is used in the treatment of shock and is employed extensively as well to enlarge the intravascular space for experimental purposes. It is usually supplied commercially as a $6 \%$ solution in $0.9 \%$ saline or $5 \%$ dextrose. The average molecular weight is about 70,000 and the solution is supposedly isoncotic with mammalian plasma.

During the pilot studies of a group of experiments in which $6 \%$ Dextran-70 in 0.9 saline (Travenol) was used to expand the plasma volume we found that this solution actually resulted in an increase in plasma volume which was considerably greater than the amount infused. For this reason we directed our attention to a study of the effective oncotic pressure of this solute. The experiments reported here indicate that commercial dextran is not isoncotic but rather hyperoncotic to canine plasma.

1 This work was supported by the National Science Foundation Grant GB-5006X.

Received: October 6, 1974; accepted: December 24, 1974. 


\section{Methods}

Female mongrel dogs weighing $15-30 \mathrm{~kg}$ were trained to stand quietly on a table. A 19-gauge needle was inserted in the right saphenous vein and $5 \mathrm{~cm}^{3}$ of blood obtained for hematocrit determination and a control plasma sample. Exactly $15 \mathrm{mg}$ of Evans blue dye was injected as a $0.5 \%$ solution using a syringe burette. Plasma samples were taken from the left saphenous vein at 30, 60,90 and 120 min following Evans blue injection, and the concentration of the dye estimated measuring optical density at $610 \mathrm{~nm}$. Control plasma was used as a blank. The four points were plotted on semilogarithmic paper and the plasma volume determined by extrapolation of the curve back to zero time. At $2 \mathrm{~h}$ after the Evans blue injection an amount of 6 or $3 \%$ dextran in $0.9 \%$ saline equal to $15-25 \%$ of the plasma volume was infused at the rate of $50 \mathrm{~cm}^{3} / \mathrm{min} .3 \%$ dextran was obtained by mixing the commercial $6 \%$ solution with $0.9 \%$ saline in $1: 1$ proportion. Initially plasma samples were taken at half hourly intervals up to $2 \mathrm{~h}$ after plasma volume expansion, analyzed for Evans blue concentration, and the values plotted on the same semilogarithmic paper as the four preexpansion Evans blue values (fig. 1). The resulting line was not parallel to the original straight line but intersected it at a time about $5 \mathrm{~h}$ after expansion. This was attributed to the fact that after expansion Evans blue concentration was altered by two factors, loss from plasma and loss of dextran and plasma volume from the circulation. Thus, the ordinate intercept of this line could not be used as the extrapolated value of Evans blue concentration at time $\mathbf{0}$ in estimating the plasma volume after expansion.

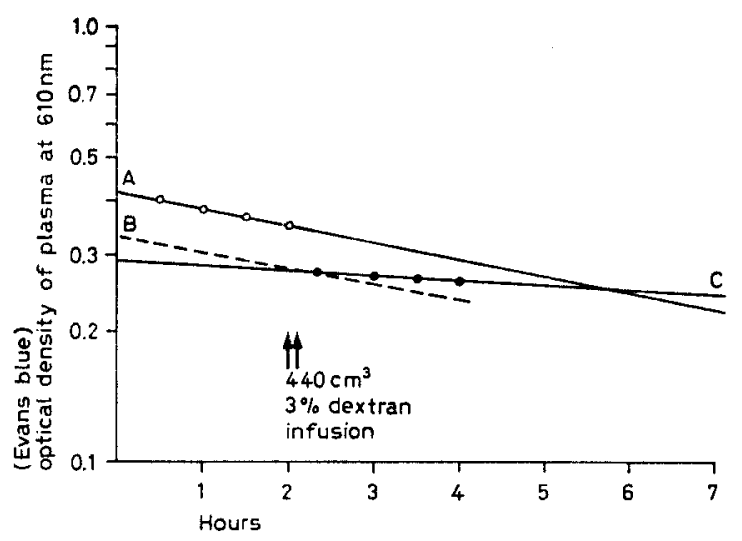

Fig. 1. Changes in concentration of Evans blue of plasma before and after expansion with $3 \%$ dextran in $0.9 \%$ saline. Point $A$ is the intercept used to calculate the control plasma volume. Point $B$ is the intercept used to calculate the plasma volume after expansion. Point $C$ is the point used to estimate the time at which plasma volume had returned to control. $\mathrm{O}=$ Control values; $\mathrm{O}=$ post-dextran infusion values. 
Instead, $20 \mathrm{~min}$ after the beginning of plasma volume expansion was chosen as the time when sufficient mixing of blood and infused solution would occur and loss of the expander from the vascular compartment would be minimal. A plasma sample was taken at this time and analyzed for Evans blue concentration. This single postexpansion value was plotted with the original four preexpansion points. A straight line was then drawn through this point parallel to the line determined by the four preexpansion values. The ordinate intercept of this line (point B) was taken as the extrapolated value of Evans blue concentration at time 0. Plasma volume after expansion was estimated using this value for Evans blue at time zero. When more than one determination was done in the same dog, there was at least a 1-week interval between experiments. Three brands of dextran were used. Dextran-70, Travenol, Dextran-75, Abbott and Macrodex 75, Pharmacia Lab. Inc.

\section{Results and Discussion}

Table I shows the results of infusing $6 \%$ dextran into 7 different dogs. All 3 brands increased plasma volume slightly more than twice the infused volume, with the average being 2.16 . In table II are shown the results of 25 determinations done on 10 dogs. In these experiments $3 \%$ dextran was infused. The mean ratio of calculated expansion: infused volume was 1.10. In 5 dogs in which Evans blue concentrations were followed for $2 \mathrm{~h}$ after expansion, the average time required for the two lines to cross (point $\mathrm{C}$ in figure 1 ) was $5 \mathrm{~h}$.

NitschmanN et al. [1967] tested the oncotic efficiency of various plasma substitutes and found it to be uniformly high. They discovered that this was due to a larger number of molecules of smaller molecular weight than advertised. On infusion this would result in a greater initial expansion of the plasma volume and a more rapid dissipation of this effect due to the disappearance of molecules in the glomerular filtrate and through capillary pores. Our findings of a high oncotic efficiency on initial infusion of $6 \%$ dextran and an apparent disappearance of the oncotic effect at about $4 \mathrm{~h}$ after infusion support these contentions.

Although it is difficult to quantitate with great precision the absolute increase in plasma volume following dextran infusion, it is evident that all three commercial brands are hyperoncotic by a factor of approximately 2 . In addition to the exaggerated plasma volume expansion it is well to keep in mind that a concomitant contraction of the interstitial space occurs. For this reason it would seem advisable for clinicians and investigators using dextran as a plasma volume expander to check on the osmotic properties of the solution to be used. 


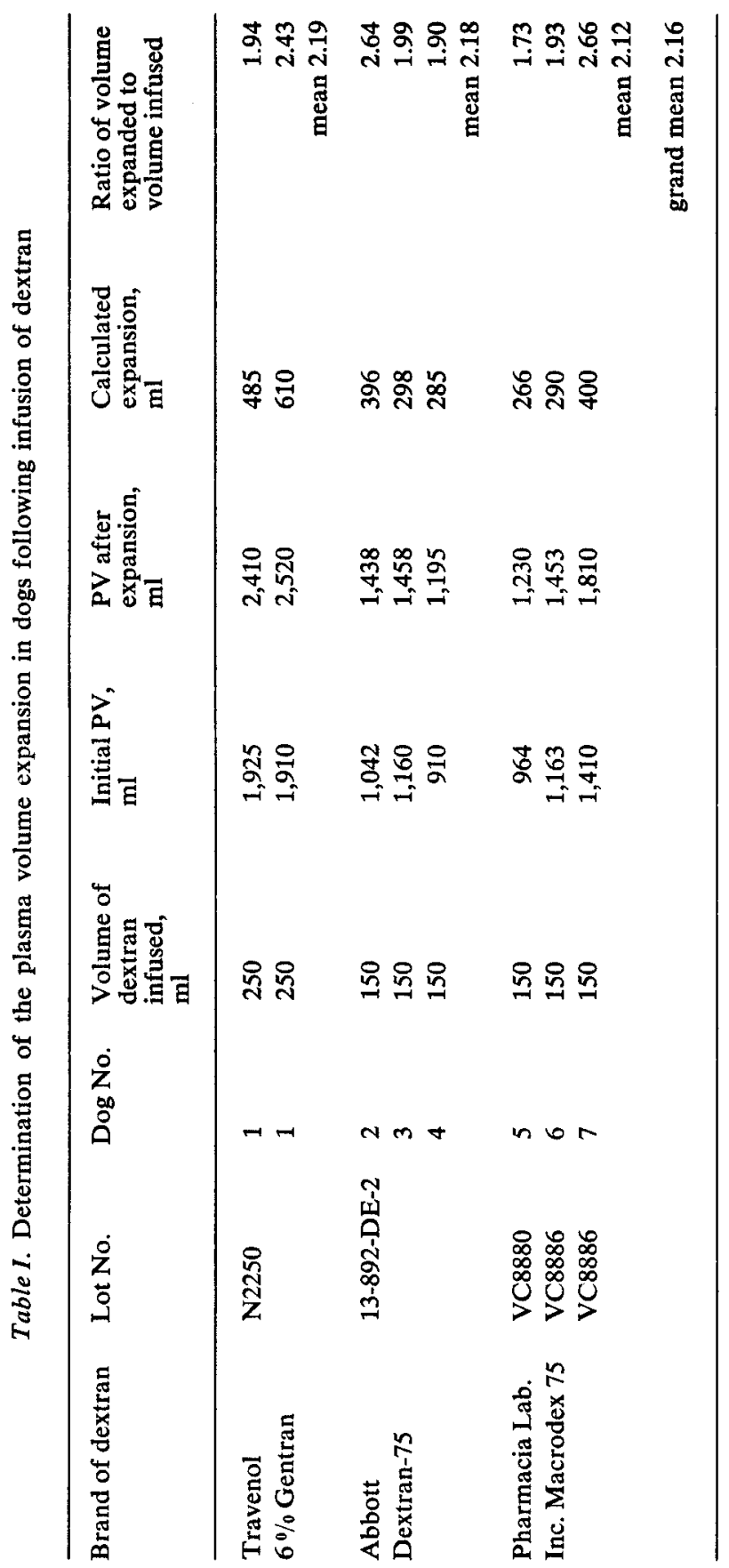


Table II. Determination of plasma volume expansion on infusion of $3 \%$ dextran (Gentran)

\begin{tabular}{cllll}
\hline Dog No. & $\begin{array}{l}\text { Number of } \\
\text { determina- } \\
\text { tions }\end{array}$ & $\begin{array}{l}\text { Volume } \\
\text { infused, } \\
\text { ml }\end{array}$ & $\begin{array}{l}\text { Calculated } \\
\text { expansion, } \\
\text { ml }\end{array}$ & $\begin{array}{l}\text { Mean ratio } \\
\text { expanded/measured }\end{array}$ \\
\hline 1 & 4 & 460 & 440 & 0.96 \\
2 & 1 & 255 & 270 & 1.06 \\
3 & 1 & 440 & 455 & 1.03 \\
4 & 2 & 360 & 370 & 1.03 \\
5 & 1 & 360 & 370 & 1.03 \\
6 & 2 & 360 & 354 & 0.98 \\
7 & 2 & 370 & 440 & 1.19 \\
8 & 4 & 360 & 385 & 1.35 \\
9 & 4 & 360 & 417 & 1.16 \\
10 & 4 & 260 & 269 & 1.04 \\
Mean \pm SE & & & & $1.10 \pm 0.04$ \\
\hline
\end{tabular}

\section{Reference}

Nitschmann, H.; Gygax, H. R.; Moser, P., and Stoll, H. R.: A simple concentration osmometer and its application to the determination of the osmotic efficiency of plasma substitutes. Vox Sang. 12: 106-117 (1967).

JohN J. MulCaHy, MD, Division of Urology, Department of Surgery, University of Kentucky, Lexington, $K Y 40506$ (USA) 